\title{
Apoptotic DNA fragmentation is detected by a semi- quantitative ligation-mediated PCR of blunt DNA ends
}

\author{
Kristina Staley ${ }^{1}$, Anne J. Blaschke ${ }^{1,2}$ and Jerold Chun ${ }^{1,3,4}$ \\ 1 The Department of Pharmacology \\ 2 Biology Graduate Program and \\ 3 Member of the Biomedical Sciences and Neurosciences Graduate Program, \\ School of Medicine, University of California, San Diego \\ 4 corresponding author: Jerold Chun, The Department of Pharmacology, School \\ of Medicine University of California, San Diego 9500 Gilman Drive La Jolla, \\ CA 92093-0636 tel: (619) 534 2659; fax: (619) 822 0041; \\ email: jchun@ucsd.edu
}

Received 10.4.96; revised 24.5.96; accepted 30.5.96 Edited by J.A. Cidlowski

\begin{abstract}
Apoptosis is a form of programmed cell death (PCD) characterized by morphological changes and stereotypical DNA degradation described as a nucleosomal 'ladder'. However, nucleosomal ladders have only been clearly demonstrated in vertebrate tissues when large numbers of cells die in synchrony. Their absence may be explained by asynchronous death under physiological conditions, or by distinct molecular mechanisms. In this study, nucleosomal ladders were revealed by a ligation-mediated polymerase chain reaction (LMPCR), that amplifies DNA fragments with blunt, 5' phosphorylated ends. Numerous tissues from different organisms were examined which demonstrated that nucleosomal ladders (a) accompany physiological cell death in mammalian tissues where previously DNA fragmentation has not been detected; (b) are produced during invertebrate cell death; (c) are invariably generated via the production of blunt, $5^{\prime}$ phosphorylated double strand breaks. These results suggest that PCD in multicellular organisms consistently involves apoptotic mechanisms and that the endonuclease activity is evolutionarily conserved.
\end{abstract}

Keywords: apoptosis, nucleosomal ladders, LMPCR

Abbreviations: PCD: programmed cell death; PCR: polymerase chain reaction; LMPCR: ligation-mediated polymerase chain reaction; CNS: central nervous system; pBS: plasmid Bluescript; ISM: intersegmental muscles

\section{Introduction}

A feature common to virtually all developing, multicellular systems is the elimination of a fraction of specific cell populations through the operation of PCD. PCD is a controlled process by which cells are eliminated in response to activation of an intrinsic program (Lockshin, 1991). Apoptosis is one form of PCD that can be recognized morphologically by plasma membrane blebbing, nucleolar breakdown and condensation of chromatin (Kerr et al, 1972; Wyllie, 1980, 1981). Associated with the loss of nuclear integrity is the endogenous, internucleosomal cleavage of genomic DNA (Wyllie, 1980; Wyllie and Morris 1982; Arends et al, 1990). The resulting oligonucleosome-sized DNA fragments $(n \times 200 \mathrm{bp})$, when visualized by gel electrophoresis, are described as a 'nucleosomal ladder', and have become a widely accepted biochemical hallmark of apoptotic cell death (Wyllie et al, 1984; Kerr and Harmen, 1991). However, to date, nucleosomal ladders have only been demonstrated in a limited number of examples of apoptosis where large numbers of cells undergo cell death in synchrony, either in response to a hormone or following pharmacological manipulation (for example in Wyllie, 1980; Alles and Sullik 1989; Rotello et al, 1989; Wood et al, 1993). Moreover, there are several reports where cells appear to die by apoptosis according to morphological criteria, but do not appear to cleave their DNA (Lockshin and Zakeri, 1991; Barres et al, 1992; Oberhammer et al, 1992). It has further been suggested that high molecular weight DNA cleavage, in the complete absence of ladder formation, may be sufficient for apoptosis to proceed normally (Cohen et al, 1992; Collins et al, 1992, Oberhammer et al, 1993). Hence, the correlation between apoptotic cell death and degradation of DNA into nucleosomal ladders has yet to be demonstrated unequivocally.

We have examined the nature of DNA ends generated during apoptosis in the model system of T-cell selection in the mammalian thymus (Surh and Sprent, 1994). Nucleosomal ladders were found to be amplified by a modified ligation-mediated polymerase chain reaction (LMPCR) that selectively amplifies DNA fragments with blunt, $5^{\prime}$ phosphorylated ends (Mueller and Wold, 1989; Schlissel et al, 1993). LMPCR was further shown to detect nucleosomal ladders in other well-established models of apoptotic cell death, including dexamethasone treatment of the mammalian thymus in vivo (Wyllie, 1980) and following induction of apoptosis by UV irradiation of neural cells in vitro (Caelles et al, 1994). LMPCR that specifically identifies $5^{\prime}$ phosphorylated, blunt DNA ends therefore appears to amplify selectively the DNA fragmentation characteristic of apoptotic cell death. We used this LMPCR technique to investigate the presence of apoptotic mechanisms in several developing systems in which cell death has been described as apoptotic according to morphological criteria, but where nucleosomal ladders have not been previously described. These include insect models of PCD, loss of neurons in the developing nervous system of Drosophila melanogaster embryos (Abrams et al, 1993; Steller and Grether, 1994) and the degeneration of intersegmental muscles (ISM) in Manduca sexta following eclosion (Schwartz and Truman, 1983, Schwartz et al, 1993). The developing mammalian cortex was also examined by LMPCR on account of previous reports of 
PCD in the postnatal period (Finlay and Slattery, 1983; Chun and Shatz, 1989; Ferrer et al, 1992, 1994). LMPCR reveals the presence of nucleosomal ladders in all these cases indicating that mechanisms characteristic of apoptosis do indeed operate in these diverse examples of developmental PCD.

\section{Results}

\section{LMPCR detects nucleosomal DNA fragmentation in the untreated mammalian thymus}

A modified LMPCR was used to investigate the nature of DNA ends generated by endonuclease activity in vivo, using T-cell development in the normal mouse thymus as a model of apoptosis (Shortman et al, 1990). A partially double-stranded oligonucleotide linker was first ligated to purified genomic DNA. The unphosphorylated structure of the linker ensured its ligation in a single orientation to $5^{\prime}$ phosphorylated DNA with compatible ends (shown for blunt-end linkers in Figure 1a). The ligated DNA was then treated with Taq polymerase to fill in $5^{\prime}$ protruding ends. This step allowed the $24 \mathrm{bp}$ linker oligonucleotide to be used as primer in subsequent PCR, and resulted in the exponential amplification of DNA fragments with linkers at both ends (Figure 1a).

The use of blunt-end linkers in LMPCR resulted in the selective amplification of nucleosomal ladders from normal thymic DNA (Figure 1b), while the use of linkers with various $5^{\prime}$ overhangs did not result in DNA amplification (data not shown; see Materials and methods). Detection of ladders was dependent on blunt-end linker ligation, since (a) no DNA fragments were detected when parallel reactions omitted T4 DNA ligase (Figure 1b); (b) following ligation and PCR amplification the size of the nucleosomal ladder fragments increased slightly, consistent with the addition of linker $24 \mathrm{bp}$ oligonucleotides at each DNA end (Figure 3a); (c) sequencing of cloned LMPCR fragments identified linker oligonucleotides at both $5^{\prime}$ ends (data not shown). In contrast, other methods used to visualize thymic genomic DNA could not distinguish nucleosomal ladders from a diffuse smear of multiple-sized fragments (Figure 1c). These methods included standard ethidium bromide staining and Southern blot analysis of electrophoresed DNA, as well as autoradiographic detection of DNA isolated from tissue sections labeled by ISEL+ (Blaschke et al, 1996) and $3^{\prime}$ end labeling of extracted DNA (Tilly, 1991,

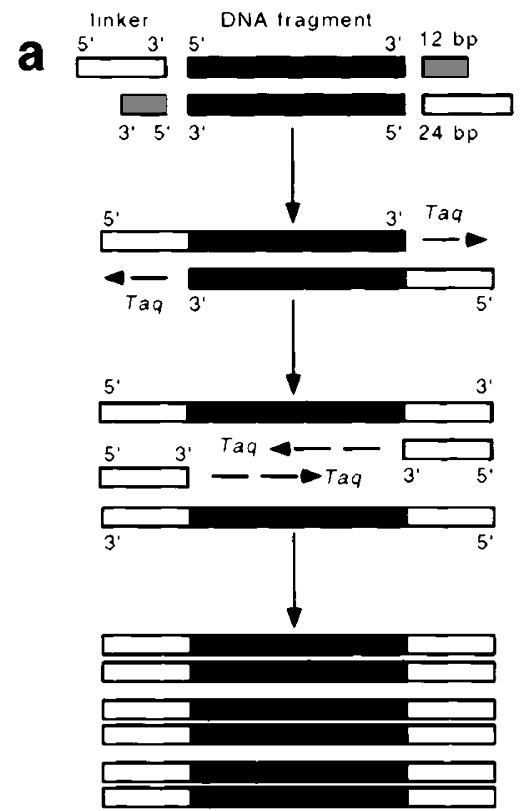

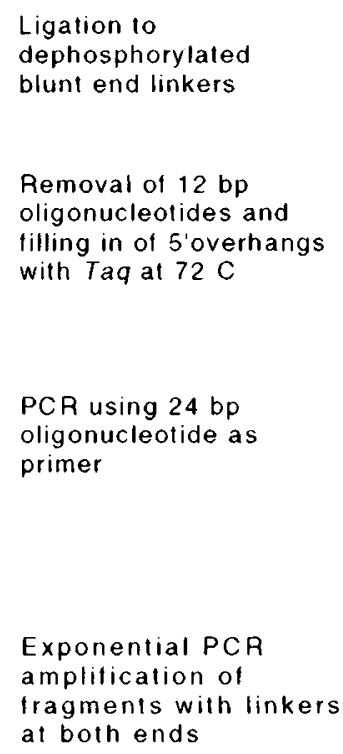

Ligation 10 dephosphorylated

Removal of $12 \mathrm{bp}$ oligonucleotides and filling in of 5 'overhangs with Taq at $72 \mathrm{C}$

tragments with linkers at both ends

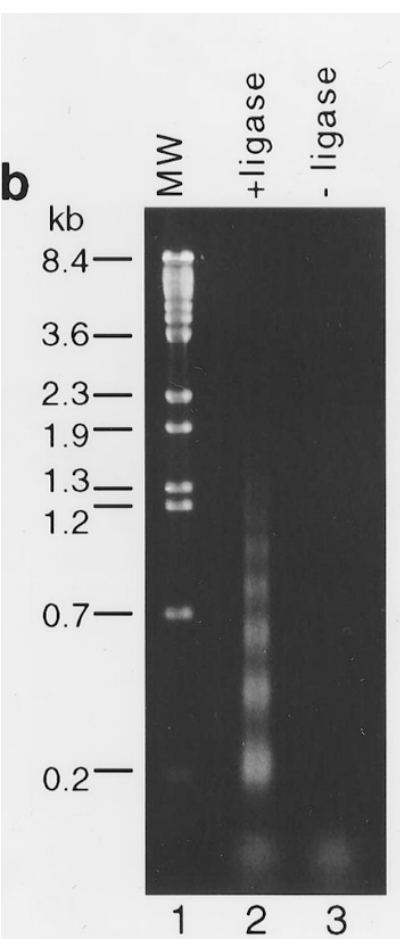

Figure 1 LMPCR analysis of DNA fragmentation in the mouse thymus. (a) Schematic diagram of the LMPCR assay using oligonucleotide linkers with blunt ends. Blunt, $5^{\prime}$ phosphorylated fragments within purified genomic DNA (black boxes) were ligated to linkers, consisting of a 24 bp oligonucleotide (open box) and a complementary $12 \mathrm{bp}$ oligonucleotide (shaded box), which formed the blunt end. Heating the ligated DNA to $72^{\circ} \mathrm{C}$ removed the $12 \mathrm{bp}$ oligonucleotides, and subsequent treatment with Taq polymerase filled in 5' protruding ends. This step enabled the 24 bp oligonucleotide to be used as a PCR primer, and resulted in the selective amplification of DNA fragments with linkers at both ends. (b) LMPCR detection of nucleosomal ladders in the normal thymus. Following blunt-end linker ligation, oligonucleosomal sized fragments were detected in normal thymic DNA (150 ng per $100 \mu$ I PCR reaction) after 26 cycles of PCR (lane 2). There was no DNA amplification following PCR of equivalent amounts of control ligation reactions that omitted ligase (lane 3 ). Lane 1 contains BstE/l digested $\lambda$ phage DNA as a molecular weight marker (MW). (c) Nucleosomal ladders were not distinguishable using standard techniques of visualizing DNA fragmentation: gel electrophoresed thymic DNA ( $1 \mu \mathrm{g}$ ) appeared as a diffuse smear following either ethidium bromide staining (lane 4), or Southern blot hybridization to ${ }^{32}$ P-labeled genomic DNA (lane 5). Autoradiographic detection of ISEL+ labeled DNA (Blaschke et al, 1996) also appeared as a smear at lower molecular weight (lane 6). 
1993). These results demonstrate that despite extensive cell death in thymic tissue, only LMPCR detects unequivocal nucleosomal ladders.

\section{Nucleosomal DNA fragments are blunt and 5' phosphorylated}

To determine whether the majority of nucleosomal DNA fragments were blunt and $5^{\prime}$ phosphorylated, thymic genomic DNA was treated with either Klenow enzyme (the large fragment of E.coli DNA polymerase I), T4 DNA polymerase or T4 polynucleotide kinase to enable linkerligation and subsequent PCR of DNA fragments with nonphosphorylated, or non-blunt ends. If a significant proportion of DNA fragments were not blunt and $5^{\prime}$ phosphorylated, these enzyme treatments would significantly alter the

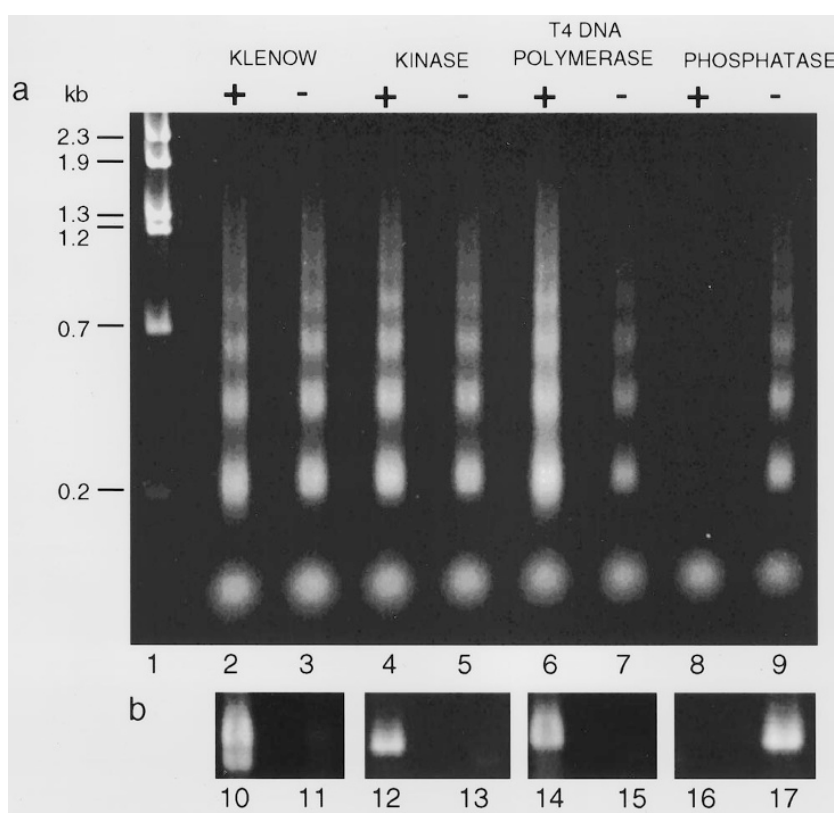

Figure 2 (a) The majority of nucleosomal ladder fragments are blunt and 5 phosphorylated. Pre-treatment of thymic DNA with Klenow to fill in 5 overhangs (lane 2) or kinase to phosphorylate DNA ends (lane 3) had little effect on subsequent amplification of nucleosomal ladders following linker ligation and LMPCR. The amplification of ladders was equivalent to that seen following LMPCR analysis of non-treated DNA (compare lanes 2 and 3 , and lanes 4 and 5). Pre-treatment with T4 DNA polymerase, which fills in 5 overhangs and removes $3^{\prime}$ overhangs to create blunt ends, (compare lanes 6 and 7), resulted in detection of ladder fragments 1-2 cycles earlier. Pretreatment with calf intestinal phosphatase removed $5^{\prime}$ phosphate groups, thus preventing linker ligation and subsequent DNA amplification (lane 8). Al samples are shown after 26 cycles of PCR. Lane 1 contains BstEll digested $\lambda$ phage DNA as a molecular weight marker (MW). (+ with enzyme treatment; untreated control). (b) The enzymes used in these experiments showed the expected activity in parallel reactions pre-treating control fragments of pBS. Klenow enzyme was shown to fill in the $5^{\prime}$ overhang on Pvull-BamHI pBS fragments of 190 and $258 \mathrm{bp}$ (lanes 10 and 11) whilst T4 DNA polymerase filled in and removed the $5^{\prime}$ and $3^{\prime}$ overhangs of a $219 \mathrm{bp} \mathrm{BamHI-Pvul} \mathrm{pBS}$ fragment respectively (lanes 14 and 15). A 448 bp Pvull pBS fragment was not detected by LMPCR after treatment with calf intestinal phosphatase (compare lanes 16 and 17) but subsequent treatment with T4 polynucleotide kinase which re-phosphorylated 5 ' hydroxyl groups, restored its amplification (lane 12).
LMPCR amplification of nucleosomal ladders to result in their detection after fewer cycles of PCR. However, filling in $5^{\prime}$ overhangs with Klenow enzyme or kinasing them with T4 polynucleotide kinase was without observable effect, while the combination of filling-in $5^{\prime}$ overhangs and removing $3^{\prime}$ overhangs with T4 polymerase slightly increased the amplification of ladders (Figure 2a, lanes 6 and 7), resulting in detection 1-2 PCR cycles earlier. Control experiments in which restriction fragments of the plasmid Bluescript (pBS) were pre-treated with these enzymes confirmed that the Klenow, T4 polymerase, and T4 kinase were active in these experiments (Figure 2b; see Materials and Methods). These results indicate that the majority of the nucleosomal-sized fragments generated in the normal mammalian thymus have $5^{\prime}$ phosphorylated blunt ends. The absolute number of fragments with these ends could not be determined because LMPCR is semiquantitative.

\section{LMPCR detects nucleosomal DNA fragmentation following induction of apoptosis}

To confirm that the nucleosomal ladders detected by LMPCR were derived from apoptotic cells, the LMPCR technique was used to examine two well-established models of apoptosis where nucleosomal ladders have been detected by standard methods, the dexamethasone-treated thymus in vivo (Wyllie, 1980) and UV irradiation induced cell death in vitro (Caelles et al, 1994) (Figure 3). Dexamethasone treatment produced a striking increase in the amount of amplified ladders, as demonstrated by their detection 10 PCR cycles earlier than from normal thymic DNA (Figure 3a). This increase in ladder amplification directly correlated with the extent of thymocyte cell death revealed by ISEL+ labeling of fragmented DNA (Blaschke et al, 1996; Figure 3b and c). Similarly, after 24 cycles of PCR, nucleosomal ladders were detected following UV irradiation of $P 19$ cells, while ladders were barely visible in genomic DNA derived from control cells (Figure 3d). The control PCR for the murine en-2 gene confirmed that equivalent amounts of genomic DNA (150 ng per $100 \mu \mathrm{l}$ PCR reaction) were used in each LMPCR assay. All ligation reactions were performed under identical conditions, and differences in the quantity of DNA fragments compensated by the addition of a vast molar excess of blunt-end linker. Furthermore LMPCR analysis of a control, blunt-end 424 bp DNA fragment, showed linear amplification over a range of 0.02-5 ng of DNA (Figure 3c), thus demonstrating a direct relationship between the amount of input DNA and the amount of LMPCR product. These observations of increased amplification of nucleosomal ladders following induction of apoptosis both in vivo and in vitro, provide evidence that the DNA fragmentation detected by LMPCR is indeed derived from apoptotic cells.

\section{LMPCR reveals differences in nucleosomal DNA fragmentation in adult tissues}

LMPCR was used to analyze genomic DNA from normal adult BALB/c mouse tissues including thymus, spleen, liver, kidney, intestine, ovary, testes and brain, all of which undergo varying 

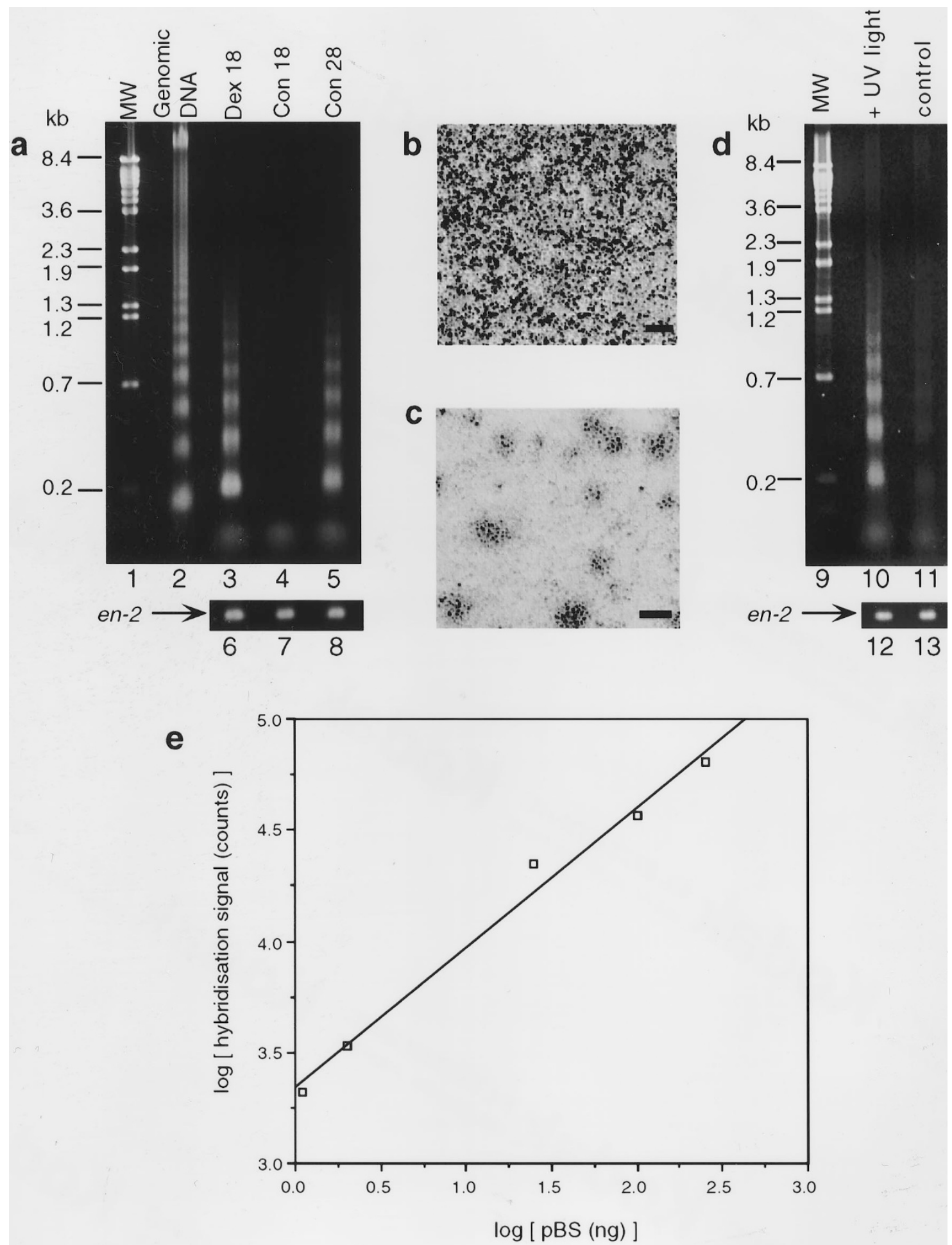

Figure 3 Semi-quantitative LMPCR analysis of nucleosomal ladder production correlates with apoptotic cell death. (a) Dexamethasone treatment of the thymus induced apoptosis and nucleosomal ladder production, which was readily detectable following gel electrophoresis and ethidium bromide staining of purified genomic DNA (1 $\mu \mathrm{g}$-lane 2). LMPCR using blunt-end linkers amplified nucleosomal ladder fragments from dexamethasone-treated thymic DNA (150 ng per $100 \mu \mathrm{l}$ PCR reaction - one-tenth reaction volume analyzed by gel electrophoresis) after just 18 cycles of PCR (lane 3; the slight increase in fragment size is due to the presence of linkers). In contrast, no ladders were detected from LMPCR analysis of untreated thymic DNA after only 18 cycles (lane 4). An additional 10 PCR cycles were required to see equivalent ladder amplification (lane 5). (Dex, dexamethasone-treated thymic DNA; Con, control (untreated) thymic DNA; 18,18 PCR cycles; 28, 28 PCR cycles) (b) ISEL+ detection of fragmented DNA reveals many more dying cells in a section of dexamethasone-treated thymus when compared to the untreated control (c) (Calibration bar=40 $\mu \mathrm{m}$ ). (d) LMPCR detects nucleosomal ladders following UV irradiation of P19 cells after 24 cycles of PCR (lane 10), whereas ladders are barely detected following LMPCR analysis of DNA from untreated cells (lane 11). Lanes 1 and 9 contain BstEIl digested $\lambda$ phage DNA as a molecular weight marker (MW). A control PCR assay for the single-copy mouse en-2 gene, confirmed that equivalent amounts of DNA (150 ng per $100 \mu$ l PCR 
degrees of cell turnover. None of these tissues underwent experimental or pharmacological manipulation prior to purification of genomic DNA. The intestine showed the most nucleosomal ladder production, since after only 22 cycles of PCR nucleosomal ladders were greatly amplified from intestinal DNA but not detectable in DNA from other tissues (Figure 4a). After an additional four cycles nucleosomal ladders became detectable in all other DNA samples although at very low levels in the adult brain (Figure 4b).

\section{LMPCR reveals nucleosomal DNA fragmentation during insect development}

To determine whether nucleosomal ladder production also accompanies developmentally regulated cell death in insects, two well established insect models of PCD were examined by LMPCR. Genomic DNA was collected from stage 12 Drosophila melanogaster embryos (Abrams et al, 1993; Steller and Gretner, 1994) and from the intersegmental muscles of Manduca sexta (tobacco hawk moth); (Schwartz et al, 1993). Subsequent LMPCR analysis revealed the presence of nucleosomal DNA fragmentation in both examples of insect PCD (Figure 5), indicating that this feature is also characteristic of apoptosis in invertebrates.

\section{LMPCR reveals relative differences in nucleosomal DNA fragmentation during mammalian CNS development}

LMPCR was used to analyze genomic DNA from the developing mouse brain in regions previously reported to undergo PCD. These included the cerebral cortex of a P7 mouse brain, and the cerebellum at P5, since earlier studies of postnatal CNS development have determined that the peak of cell death occurs in these regions at these time points (Finlay and Slattery, 1983; Ferrer et al, 1992; Wood et al, 1993). For comparison, genomic DNA was also isolated from the brains of E14 embryos and adult mice. As expected, nucleosomal ladders were detected by LMPCR analysis of the P5 cerebellum and the P7 cortex (Figure 6 lanes 4 and 5), and were absent in the adult CNS (Figure 6 - lane 3). Surprisingly, nucleosomal ladder fragments were also amplified from genomic DNA derived from E14 brains, at levels comparable to those observed in the postnatal cerebellum, cortex and thymus. These results indicate the operation of mechanisms characteristic of apoptosis in the developing forebrain and further suggest that CNS cell death may not only occur here during the postnatal period, but may also be of earlier significance in the embryo.

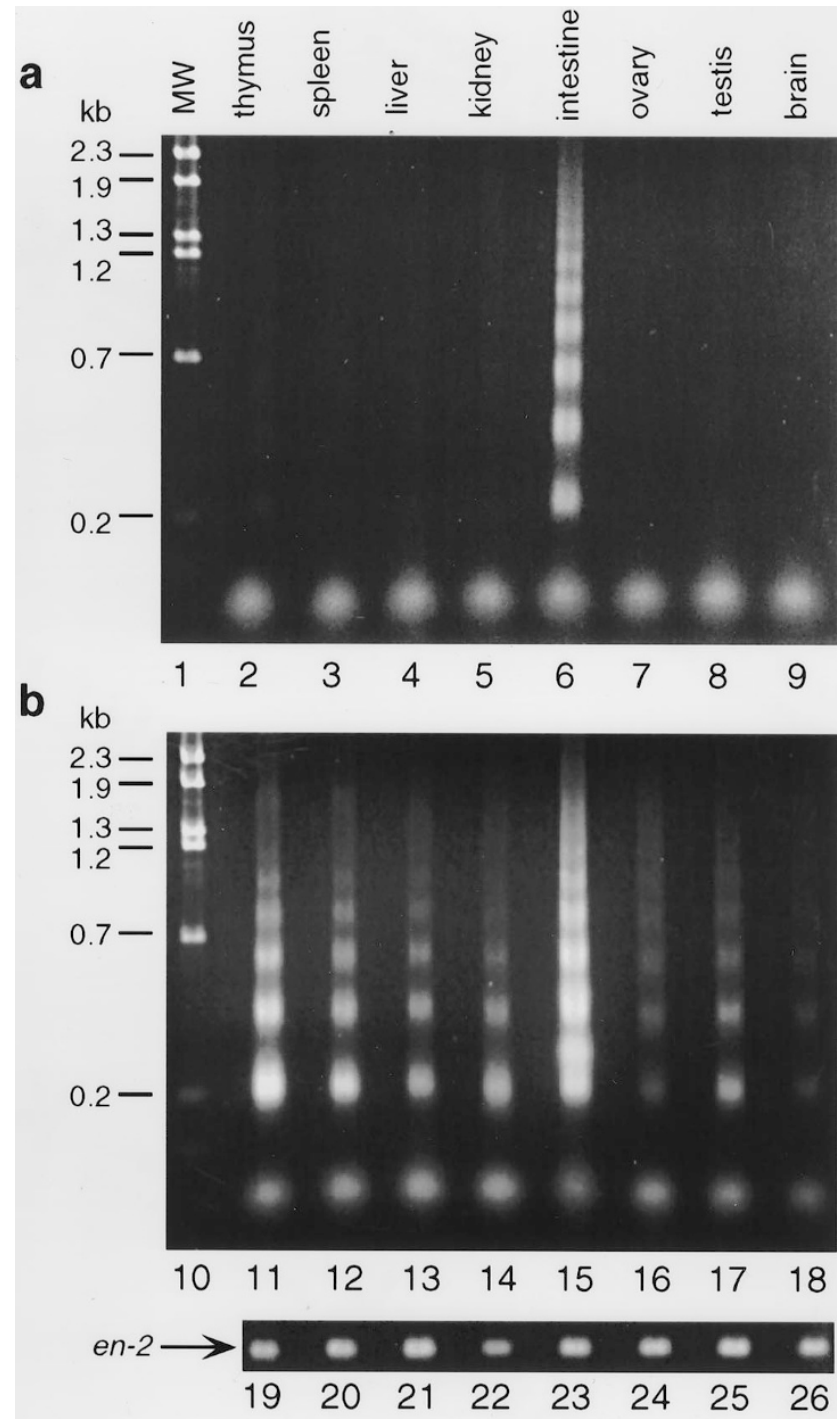

Figure 4 LMPCR analysis of nucleosomal ladder production in adult mouse tissues. (a) Following blunt-end linker ligation, nucleosomal ladders were detected in DNA from adult intestine after 22 cycles of PCR (lane 6), which correlates with the very high rate of cell turnover in the intestinal epithelium (Cotran et al, 1989). Ladders were barely detectable in DNA from other tissues after this number of PCR cycles. (b) After an additional 4 PCR cycles, nucleosomal ladders were also detected in thymus, spleen, liver, kidney, ovary and testes (lanes 11, 12, 13, 14, 16 and 17 respectively). Ladders were barely detectable in adult brain after 26 cycles of PCR (lane 18), which correlates with the limited amount of CNS cell turnover restricted primarily to the glial cell population. A control PCR assay for the en-2 gene, confirmed that equivalent amounts of DNA (150 ng per $100 \mu \mathrm{l}$ PCR reaction) were analyzed by LMPCR (lanes 19-26). Lane 1 contains BstEll digested $\lambda$ phage DNA as a molecular weight marker (MW).

reaction) were analyzed by LMPCR (control PCR carried out at cycle number prior to saturation - lanes $6,7,8,12$ and 13). (e) Linear amplification of blunt, 5 phosphorylated DNA fragments by LMPCR. Quantification of a blunt-end pBS fragment after 24 cycles of PCR, showed linear amplification following addition of $0.02-5 \mathrm{ng}$ of plasmid DNA to ligation reactions. Each data point represents an average of three independent LMPCR experiments (described in Materials and Methods). These results indicate that within the exponential range of PCR cycle number, there is a linear relationship between the amount of DNA added to the blunt-end linker ligation reaction and the number of blunt end fragments amplified by PCR. Hence, quantitative differences in nucleosomal ladder amplification by LMPCR (as shown in a and b) directly correlate with the number of ladder fragments present in each DNA sample. 


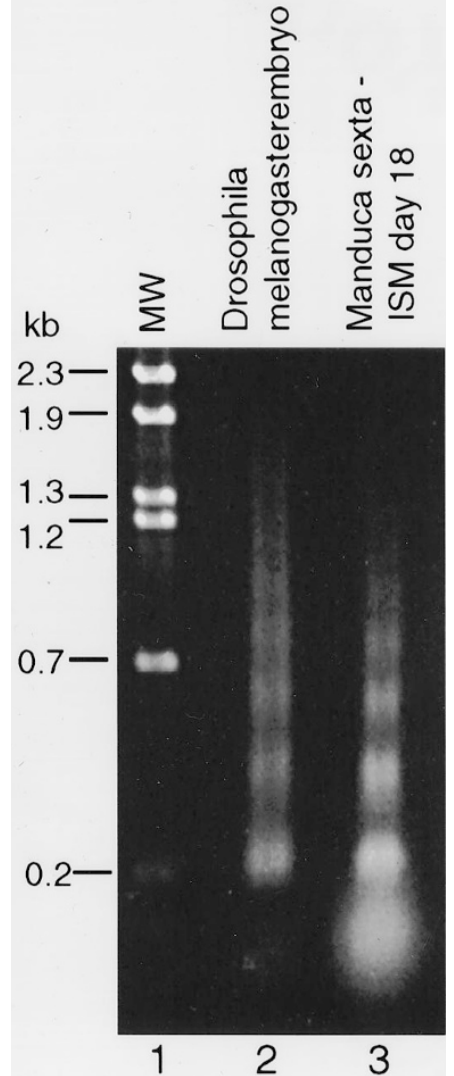

Figure 5 LMPCR analysis of DNA fragmentation accompanying cell death in insects. Following linker ligation and PCR, nucleosomal ladders were amplified from genomic DNA isolated from stage 12 Drosophila melanogaster embryos (lane 2-26 cycles), where extensive cell death has been previously classified as apoptotic according to morphological criteria (Abrams, 1993; Steller, 1994). Nucleosomal ladders were also detected by LMPCR analysis of genomic DNA from the ISM of day 18 Manduca sexta where cell death results muscle loss following eclosion (lane 3-18 cycles). These results contrast with previous lack of evidence for DNA fragmentation in the ISM (Schwartz et al, 1993) and suggest that mechanisms characteristic of apoptosis may indeed determine cell loss in the degenerating ISM. Lane 1 contains BstEll digested $\lambda$ phage DNA as a molecular weight marker (MW).

\section{Discussion}

Although apoptosis appears to be a common feature of most, if not all developing multicellular systems, a biochemical marker for apoptotic cell death, namely nucleosomal ladders, has not been observed uniformly in all tissues of all organisms. The reason for this appears to be an issue of sensitivity, based on the results of the LMPCR studies presented here. LMPCR specifically amplifies DNA fragments derived from apoptotic cells, since at low PCR cycle number (18 cycles) nucleosomal ladders cannot be detected in normal thymic tissue, in contrast to massive amplification from a dexamethasone treated thymus after the same number of cycles of PCR. Similarly, nucleosomal ladders are barely detected in untreated P19 cells, while UV irradiation results in considerable LMPCR nucleosomal ladder amplification after 24 cycles of PCR. In addition, LMPCR amplification of ladders is always observed in all tissues in which apoptosis is known to occur. The sensitivity of the technique is emphasized by its ability to detect

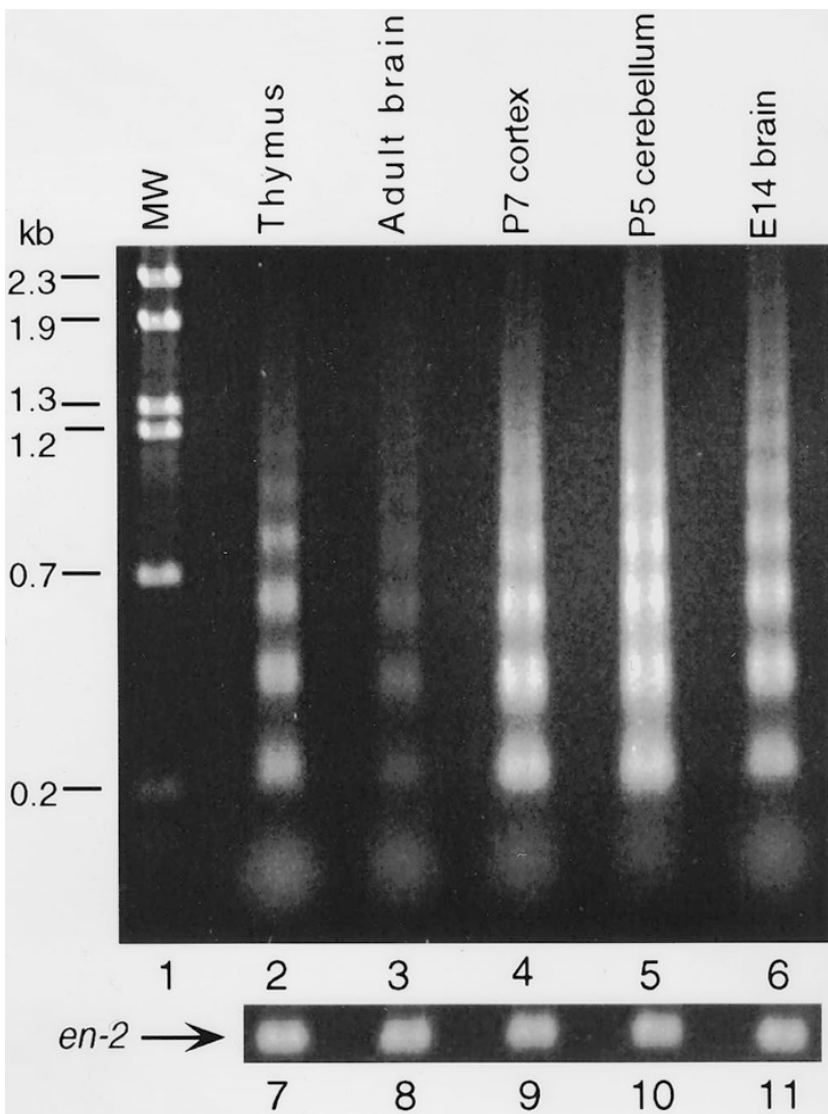

Figure 6 LMPCR analysis of nucleosomal ladder production in the developing mammalian CNS. Following blunt-end linker ligation nucleosomal ladders were amplified from genomic DNA derived from P7 cortex and P5 cerebellum (lanes 4 and 5) corresponding to previously reported peaks of cell death in the postnatal brain. Few nucleosomal ladders were amplified from adult brain genomic DNA (lane 3) where there is no evidence for significant loss of cells (Finlay and Slattery, 1983; Ferrer et al, 1992; Wood et al, 1993). Surprisingly, a comparable level of nucleosomal ladders was amplified from the forebrain of an E14 mouse (lane 6), where previously cell death has not been described. All samples are shown after 26 cycles of PCR. LMPCR analysis of adult mouse thymic genomic DNA is shown for comparison (lane 2). These results suggest that apoptotic mechanisms begin to operate during the fetal development of the mammalian brain, and are then extended into postnatal development. The spatial distribution of this cell death was recently demonstrated by an in situ end labeling technique (ISEL+) (Blaschke et al, 1996). Lane 1 contains BstEll digested $\lambda$ phage DNA as a molecular weight marker (MW).

apoptotic DNA fragmentation even when the number of dying cells constitutes a small percentage of the total cell population, as in normal adult tissue turnover. More significantly, the combined sensitivity and specificity of the LMPCR technique has enabled the detection of apoptotic mechanisms in developing organisms and tissues where nucleosomal ladders or apoptosis had not been previously described.

In the normal thymus, LMPCR detects nucleosomal ladders whereas other DNA detection methods reveal a smear of many-sized fragments. In this well-accepted model of apoptotic cell death, over $95 \%$ of cells undergo apoptosis (Shortman et al, 1990), but the asynchronous nature of their death results in relatively few cells actively cleaving their DNA at any one time. Using standard 
methods, such $3^{\prime}$ end labeling and gel electrophoresis followed by ethidium bromide staining (Tilly, 1991; Tilly and Hseuh, 1993; Blaschke, 1996), the initial products of DNA fragmentation, the nucleosomal ladders, are difficult to distinguish from intermediate-sized fragments derived from further degradation of DNA. The fact that LMPCR is able to detect ladders in thymic DNA therefore indicates that LMPCR selectively amplifies an initial product of DNA cleavage. In this regard LMPCR provides 'specificity' combined with increased sensitivity, of considerable advantage over other methods of detecting DNA fragmentation. Pre-treatment of thymic DNA with various enzymes to alter the state of the DNA ends slightly increased subsequent nucleosomal ladder amplification only in the case of T4 DNA polymerase, which creates blunt ends from both $5^{\prime}$ and $3^{\prime}$ overhangs. Hence, a proportion of nucleosomal DNA fragments do appear to have non-blunt ends. For this reason, ladders can be detected by methods based on end-labeling with Klenow as described in Rosl (1992). However, since T4 polymerase treatment results in detection of nucleosomal ladders only 1-2 cycles earlier than a non-treated control, it would seem that the majority of fragments in fact are blunt and $5^{\prime}$ phosphorylated. Therefore, an early and stable event during nucleosomal DNA fragmentation appears to be the generation of blunt, $5^{\prime}$ phosphorylated double strand breaks. Little is known about the endonuclease(s) responsible for ladder production besides its dependence on $\mathrm{pH}$ and the presence of $\mathrm{Ca}^{2+}$ or $\mathrm{Mg}^{2+}$ ions in mammals (Cohen and Duke, 1984; Arends et al, 1990). Several candidate nucleases have been proposed, including DNase I (Ucker et al, 1992; Peitsch et al, 1993), DNase II (Barry and Eastman, 1993) and Nuc 18 (Caron-Leslie et al, 1991); hence, identifying enzymes which produce DNA fragments with blunt, 5' phosphorylated ends may help to discern the nucleases that have a physiological role. We note that the only endonuclease activity shown to generate these types of DNA ends in vivo is the $V(D) J$ recombinase encoded in part by RAG-1 and RAG-2 (Schlissel et al, 1993) which could conceivably participate in ladder production in the thymus, and perhaps the CNS where RAG-1 is expressed (Chun et al, 1991).

Nucleosomal DNA fragmentation can be detected by LMPCR in a range of tissues from the adult mouse, where apoptosis is thought to counterbalance cell proliferation and maintain tissue size (Kerr et al, 1972), but where nucleosomal ladders have not been previously described. DNA fragmentation may have previously fallen below the threshold of standard methods of detection, since dying cells need only form a small percentage of total tissue mass (an estimated $2-3 \%$ ) to obtain substantial daily regression of tissue (Bursch et al, 1990). It is likely that the nucleosomal ladders observed with LMPCR are derived from apoptotic cell death accompanying homeostatic regulation (Hinsull and Bellamy, 1981) since none of the tissues examined underwent experimental manipulation prior to isolation of DNA. More nucleosomal-sized fragments were detected in tissues undergoing rapid cell turnover, such as the intestine, than in tissues with slow cell turnover, such as the brain (Gavrieli et al, 1992). These results highlight the sensitivity of the LMPCR technique in being able to detect DNA fragmentation when only few cells in a given population are dying. By comparison, other reports of sensitive methods of ladder detection are able to detect fragmentation in few cells (i.e.: with a small amount of starting material) when the entire cell population is dying in synchrony, as for example in atretic ovarian follicles (Tilly et al, 1991 and Tilly and Hsueh, 1993; Piquette et al, 1994). The limits of detection of the LMPCR technique have not been established, but by increasing the number of PCR cycles it remains formally possible to amplify ladders from very small amounts of DNA, even to analyze DNA fragmentation in a single cell. In this way LMPCR may provide by far the most sensitive means of ladder detection; moreover, analysis of this kind may answer the question as to whether ladder production actually occurs within the cell undergoing apoptosis as opposed to phagocytes, and help determine whether nucleosomal fragmentation is a necessary and/or sufficient step in the cell death process.

Through LMPCR analysis, nucleosomal ladder production has been demonstrated in stage 12 Drosophila melanogaster embryos, where histological analysis reveals widespread apoptotic cell death (Abrams et al, 1993; Steller and Grether, 1994). Consistent with this result, is the observation that ladders are also amplified from the ISM of day 17-18 Manduca sexta. The ISM are present in both larval and pupal stages, but are rapidly removed around the time of emergence (day 18) since they are no longer required in the adult (Schwartz and Truman, 1983). Previous studies identified morphological changes in dying ISM cells distinct from those observed in the thymic model of apoptotic cell death, which, in conjunction with the apparent absence of nucleosomal ladders, was interpreted as evidence for an alternate mechanism of PCD (Schwartz et al, 1993). However, the demonstration of nucleosomal ladders using LMPCR, suggests that the death of ISM in fact does involve some features characteristic of apoptosis, at least involving a final common pathway for degrading DNA. LMPCR has thus provided the first demonstration of internucleosomal DNA cleavage during invertebrate cell death, suggesting that mechanisms of DNA fragmentation are evolutionarily conserved. A phylogenetic study using LMPCR to examine DNA degradation accompanying cell death in simpler organisms will determine the extent of this conservation.

The detection of nucleosomal ladders following LMPCR analysis of the developing CNS revealed the operation of apoptotic mechanisms where previously cell death had not been thought to occur. PCD has been described in the postnatal cortex, where cell loss determines local features of neocortical differentiation (Finlay and Slattery, 1983; Ferrer et al, 1992, 1994), as well as in the postnatal cerebellum, where cell loss is involved in establishing appropriate matching of neurons to targets (Wood et al, 1993). As expected, LMPCR analysis of P7 cerebral cortex and P5 cerebellum revealed that this developmentally regulated cell death is indeed accompanied by apoptotic nucleosomal DNA fragmentation. Similarly, few nucleosomal ladder fragments were amplified from adult brain DNA, in accordance with lack of evidence for apoptotic cell death. Surprisingly, LMPCR analysis of genomic DNA from E14 
forebrain showed significant amplification of nucleosomal ladders, where apoptosis has not been previously described. These results are consistent with the operation of extensive cell death in the mammalian forebrain during the prenatal period, suggesting a role for apoptosis in regulating the development of the embryonic CNS, in concordance with our recent report (Blaschke et al, 1996).

The LMPCR technique provides a new sensitive and specific means for identifying the characteristic DNA fragmentation associated with apoptosis, particularly under physiological conditions in vivo. Future use of LMPCR analysis may help to shed light on the nature of the endonuclease/s responsible for generating nucleosomal ladders and aid the investigation of the prevalence of apoptotic mechanisms accompanying PCD; previous examples of cell death thought to proceed in the absence of ladder production, would particularly merit further examination using this approach. The results presented here also demonstrate that nucleosomal DNA fragments are generated with blunt, $5^{\prime}$ phosphorylated ends in organisms as diverse as insects and mammals. Hence, it appears that apoptotic DNA degradation may be a universal feature of $P C D$ in multicellular organisms and furthermore that the mechanisms responsible for ladder production may be phylogenetically conserved.

\section{Materials and Methods}

\section{DNA isolation}

Genomic DNA for examination by LMPCR was isolated from representative tissue samples from adult BALB/c mice $(n=26)$, postnatal mice on postnatal days 5 and 7 (P5 and P7) ( $n=8$ on each day) and embryonic day 14 (E14) embryos $(n=20)$. Tissue samples included thymus, spleen, liver, kidney, intestine, ovaries, testes and brain which were rapidly dissected and immediately frozen in liquid nitrogen. The tissue was crushed before resuspension in digestion buffer (75 mM NaCl, $10 \mathrm{mM}$ Tris-HCl pH 8.0, $25 \mathrm{mM}$ EDTA, 1\% SDS) and treatment with proteinase $\mathrm{K}(0.4 \mathrm{mg} / \mathrm{ml})$ for $12-16 \mathrm{~h}$ at $50^{\circ} \mathrm{C}$. The cerebral cortices dissected from the brains of embryonic mice on $E 10$, $\mathrm{E} 12, \mathrm{E} 14, \mathrm{E} 16, \mathrm{E} 18(n=6-8)$ were immediately placed in digestion buffer and similarly treated with proteinase $\mathrm{K}$. After phenol/chloroform and chloroform extractions, the DNA was ethanol precipitated with $0.3 \mathrm{M}$ sodium acetate, recovered by spooling (DNA pelleted by centrifugation produced identical LMPCR results), washed in $70 \%$ ethanol, air dried and resuspended in TE $(10 \mathrm{mM}$ Tris- $\mathrm{HCl}, 1 \mathrm{mM}$ EDTA, pH 8.0). DNA was extracted from insect tissue samples using an identical procedure after the following tissue preparation: Drosophila melanogaster - whole, stage 12 embryos were treated with bleach to remove chitinous exoskeleton (Kamakaka et al, 1991); Manduca sexta - intersegmental muscles (ISM) were dissected from day 17-18 moths (staged as described in Schwartz and Truman, 1983). At least three independent samples of DNA were obtained from each tissue and analyzed by gel electrophoresis, to confirm that the DNA had not be degraded during preparation (data not shown). DNA samples were quantified fluorimetrically (Hoefer Scientific Instruments, San Francisco).

\section{Dexamethasone treatment}

Four, 18 day old mice were injected intraperitoneally with $5 \mathrm{mg} / \mathrm{kg}$ dexamethasone (Sigma Chemical Co., St. Louis) in 10\% ethanol in saline, and their thymuses removed $8 \mathrm{~h}$ later. Thymuses were also removed from four age-matched control animals $8 \mathrm{~h}$ after injection with $10 \%$ ethanol in saline. Genomic DNA was extracted as described above.

\section{Irradiation of P19 cells}

$2.5 \times 10^{5}$ P19 cells (Rudnicki and McBurney, 1987) were plated in $90 \mathrm{~mm}$ plates in medium (Opti-MEM I (Gibco) supplemented with $5 \%$ fetal calf serum, $20 \mathrm{mM}$ glucose, $55 \mu \mathrm{M} \beta$-mercaptoethanol, and $1 \%$ penicillin-streptomycin), and incubated at $37^{\circ} \mathrm{C}$ for $24 \mathrm{~h}$. Before UV irradiation, the medium was removed from experimental and control plates and the cells washed in pre-warmed PBS. After UV irradiation $\left(80 \mathrm{~J} / \mathrm{m}^{2}\right.$ in GS Genelinker; BioRad), $2 \mathrm{ml}$ of prewarmed medium was added and the plates returned to the incubator. After $10 \mathrm{~h}$, the cells were scraped into $2 \mathrm{ml}$ of culture medium, and equal volume of two $\times$ digestion buffer added. After overnight incubation at $55^{\circ} \mathrm{C}$, the DNA was phenol/chloroform extracted and ethanol precipitated.

\section{Ligation-mediated PCR}

Genomic DNA $(1.0 \mu \mathrm{g})$ was mixed with $1 \mathrm{nmol}$ each of $24 \mathrm{bp}$ and $12 \mathrm{bp}$ unphosphorylated oligonucleotides in $60 \mu \mathrm{l}$ of T4 DNA ligasive buffer (Boehringer Mannheim, Indianapolis). Oligonucleotides were annealed by heating to $55^{\circ} \mathrm{C}$ for $10 \mathrm{~min}$, allowing the mixture to cool to $10^{\circ} \mathrm{C}$ over $55 \mathrm{mim}$, and incubating the reaction at $10^{\circ} \mathrm{C}$ for $10 \mathrm{~min}$. $3 \mathrm{U}$ of T4 DNA ligase (Boehringer Mannheim) were added and ligations incubated at $16^{\circ} \mathrm{C}$ for $12-16 \mathrm{~h}$. The reactions were then diluted with $\mathrm{TE}$ to a final concentration of $5 \mathrm{ng} / \mu \mathrm{l}$. Samples were stored at $-20^{\circ} \mathrm{C}$ until PCR. The sequences of blunt-end linkers used to amplify nucleosomal ladders were $24 \mathrm{bp}$ : 5'-AGCACTCTCGAGCCTCTCACCGCA-3' and 12 bp: 5'-TGCGGTGAGAGG-3'. Other linkers with BgIII, HindIII and BamHI compatible ends used in preliminary studies have been described in Lisitsyn et al (1993). These never amplified DNA fragments from normal thymic DNA. Ligated DNA (150 ng) was used in a PCR assay (100 $\mu$ lvolume) containing $124 \mathrm{pmol}$ of the $24 \mathrm{bp}$ linker primer, $67 \mathrm{mM}$ Tris- $\mathrm{HCl} \mathrm{pH}$ 8.8, $2 \mathrm{mM} \mathrm{MgCl}_{2}, 16 \mathrm{mM}\left(\mathrm{NH}_{4}\right)_{2} \mathrm{SO}_{4}$ $10 \mathrm{mM} \beta$-mercaptoethanol, $100 \mu \mathrm{g} / \mathrm{ml} \mathrm{BSA}, 320 \mu \mathrm{M}$ (each) dATP, dCTP, dTTP and overlaid with mineral oil. The tubes were heated to $72^{\circ} \mathrm{C}$ for $3 \mathrm{~min}, 5 \mathrm{U}$ of $\mathrm{Taq}$ polymerase (Gibco, Bethesda) added per $100 \mu \mathrm{l}$ reaction, and 5 protruding ends of the ligated adapters filled in by incubation at $72^{\circ} \mathrm{C}$ for an additional $5 \mathrm{~min}$. Samples were amplified for $20-30$ cycles of $1 \mathrm{~min}$ at $94^{\circ} \mathrm{C}$ and $3 \mathrm{~min}$ at $72^{\circ} \mathrm{C}$. As an internal control, normal thymic DNA was ligated to blunt-end linkers and analyzed after a standard number of PCR cycles. PCR products $(15 \mu \mathrm{l})$ were analyzed by electrophoresis through $1.2 \%$ agarose gels equilibrated in $45 \mathrm{mM}$ Tris-borate, $1 \mathrm{mM}$ EDTA buffer $\mathrm{pH}$ 8.0. After electrophoresis for $2 \mathrm{~h}$ at $6 \mathrm{~V} / \mathrm{cm}$, gels were stained by ethidium bromide and photographed on a UV transilluminator. DNA from agarose gels was transferred in $0.4 \mathrm{M} \mathrm{NaOH}$ to GeneScreen Plus nylon membranes (DuPont NEN, Boston). The filter was neutralized in $0.1 \mathrm{M}$ Tris- $\mathrm{HCl} \mathrm{pH} \mathrm{7.5,2 \times SSC}$ and UV crosslinked, before hybridizing overnight at $65^{\circ} \mathrm{C}$ with random primed ${ }^{32} \mathrm{P}$-labeled EcoRl digested genomic DNA under high stringency.

Control PCR for en-2: Identical amounts of ligated DNA (150 ng) were used in $100 \mu \mathrm{l} \mathrm{PCR}$ (buffer as described above except for the presence $4 \mathrm{mM} \mathrm{MgCl} 2 ; 50 \mu \mathrm{M}$ each dNTP; 100 pmol of each oligonucleotide 5'AGGACAAGCGGCCTCGCACA-3' and 5'-CGGTGTCCGACTTGCCCTC-3' and $2.5 \cup$ Taq polymerase). The samples were amplified for 26 cycles of PCR; $1 \mathrm{~min}$ at $94^{\circ} \mathrm{C}, 1 \mathrm{~min}$ at $70^{\circ} \mathrm{C}$ and $1 \mathrm{~min}$ at $72^{\circ} \mathrm{C}$. Analysis of standard amounts of DNA (50-150 ng) confirmed linear amplification of the $270 \mathrm{bp}$ en-2 fragment at this cycle number (data not shown). 
Quantitative analysis of LMPCR: A blunt, $424 \mathrm{bp}$ Pvull fragment of pBS was serially diluted to obtain a range of concentrations, $5-0.02 \mathrm{ng} / \mu \mathrm{l}$ and $1 \mu \mathrm{l}$ of each dilution added to standard LMPCR ligation reactions containing liver genomic DNA $(2.5 \mu \mathrm{g})$ to approximate actual LMPCR conditions. After blunt-end linker ligation and 24 cycles of PCR (mid-range in cycle number), $15 \mu \mathrm{l}$ of the $100 \mu \mathrm{l} \mathrm{PCR}$ reaction were gelelectrophoresed, transferred to nylon GeneScreen Plus membrane as described above, and hybridized to ${ }^{32} \mathrm{P}$-labeled pBS under stringent conditions. After washing, the hybridization signal was quantified by phosphorescence imaging (Bio-Rad, Hercules).

Enzyme treatments: Thymic genomic DNA $(2.5 \mu \mathrm{g})$ was treated with either Klenow enzyme (50 mM Tris- $\mathrm{HCl} \mathrm{pH} 7.5,10 \mathrm{mM} \mathrm{MgCl}_{2}, 1 \mathrm{mM}$ DTT, $50 \mu \mathrm{g} / \mathrm{ml} \mathrm{BSA}, 20 \mu \mathrm{M}$ (each) dATP, dCTP, dGTP, dTTP, $2 \mathrm{U}$ enzyme; $30 \mathrm{~min}$ at $\left.37^{\circ} \mathrm{C}\right)$; T4 DNA polymerase $(50 \mathrm{mM}$ Tris- $\mathrm{HCl} \mathrm{pH} \mathrm{7.5,}$ $5 \mathrm{mM} \mathrm{MgCl}_{2}, 5 \mathrm{mM}$ DTT, $50 \mu \mathrm{g} / \mathrm{ml} \mathrm{BSA}, 300 \mu \mathrm{M}$ (each) dATP, dCTP, dGTP, dTTP, $2 \mathrm{U}$ enzyme; $20 \mathrm{~min}$ at $37^{\circ} \mathrm{C}$ ) or T4 polynucleotide kinase (50 mM Tris- $\mathrm{HCl} \mathrm{pH} \mathrm{7.5,} 5 \mathrm{mM} \mathrm{MgCl}, 5 \mathrm{mM}$ DTT, $50 \mu \mathrm{g} / \mathrm{ml} \mathrm{BSA}, 1 \mathrm{mM}$ ATP, $10 \mathrm{U}$ enzyme, $1 \mathrm{~h}$ at $37^{\circ} \mathrm{C}$ ), (all enzymes from Boehringer Mannheim, Indianapolis). Parallel control reactions omitted enzyme. Enzymes were removed by phenol/chloroform extraction and the DNA purified by ethanol precipitation in the presence of $10 \mu \mathrm{g}$ tRNA as carrier. The DNA precipitate was resuspended in TE, ligated to the blunt-end linker and subjected to PCR as previously described. A comparison was then made between amplification of nucleosomal ladders in enzymetreated DNA and non-treated controls. Under parallel conditions, Klenow enzyme was shown to fill in the $5^{\prime}$ overhang on a Pvull-BamHI pBS fragment and T4 DNA polymerase to fill in and remove the $5^{\prime}$ and $3^{\prime}$ overhangs of a BamHI-Pvul pBS fragment respectively. A Pvull pBS fragment was not detected by LMPCR after treatment with calf intestinal phosphatase, but subsequent treatment with T4 polynucleotide kinase which re-phosphorylated $5^{\prime}$ hydroxyl groups, restored its amplification (Figure 2b).

Terminal deoxynucleotidyl transferase (TdT)-labeled tissue analysis: Sections from an adult mouse thymus were prepared and analyzed by ISEL+ using ${ }^{32} \mathrm{P}$-labeled nucleotide, as described in Blaschke et al (1996). The tissue section was scraped from the slide and DNA isolated using the standard procedure described above. Alternatively, DNA extracted from thymic tissue was $3^{\prime}$ end labeled with TdT using a similar procedure (Blaschke et al, 1996). The labeled DNA was gel electrophoresed, the gel dried and exposed to autoradiographic film.

\section{Acknowledgements}

We wish to thank the following individuals for their generous gifts of organisms and expert advice: Drs. J. Tyler and J.T. Kadonaga (fruit fly); Drs. S. Reiss and J.W. Truman (tobacco hawkmoth). We thank Drs. K. Murre and D. Sretavan for reading the manuscript, and C. Akita for her expert technical assistance. This research was supported by the Esther A. and Joseph Klingenstein Fund and the California Tobacco-Related Disease Program (JC) and by the Pharmacology Training Grant (AB).

\section{References}

Abrams JM, White K, Fessier LI and Steller H (1993) Programmed cell death during Drosophila embryogenesis. Dev. 117: 29-43

Alles AJ and Sulik KK (1989) Retinoic-acid-induced limb reduction defects: perturbation of zones of programmed cell death as a pathogenic mechanism. Teratol. 40: 163-171

Arends MJ, Morris RG and Wyllie AH (1990) Apoptosis; the role of the endonuclease. Am. J. Path. 136: 593-608

Barres BA, Hart IK, Coles HSR, Burne JF, Voyvodic JT, Richardson WD and Raff MC (1992) Cell death and control of cell survival in the oligodendrocyte lineage. Cell 70: $31-46$
Barry MA and Eastman A (1993) Identification of deoxyribonuclease II as an endonuclease involved in apoptosis. Arch. Biochem. Biophys. 300: 440-450

Blaschke AJ, Staley K and Chun J (1996) Widespread programmed cell death in proliferative and postmitotic regions of the fetal cerebral cortex. Development 122: $1165-1174$

Bursch W, Kleine L and Tenniswood M (1990) The biochemistry of cell death by apoptosis. Biochem. Cell Biol. 68: 1071-1074

Caelles C, Helmberg A and Karin M (1994) p53-Dependent apoptosis in the absence of transcriptional activation of p53-target genes. Nature 370: 220-223

Caron-Leslie LM, Schwartzman RA, Gaido ML, Compton MM and Cidlowski JA (1991) Identification and characterization of glucocorticoid-regulated nuclease(s) in lymphoid cells undergoing apoptosis. Steroid Biochem. Mol. Biol. 40: $661-671$

Chun JJM, Schatz DG, Oettinger MA, Jaenisch R and Baltimore D (1991) The recombination activating gene-1 (RAG-1) transcript is present in the murine central nervous system. Cell 64: 189-200

Chun JJM and Shatz CJ (1989) Interstitial cells of the adult neocortical white matter are the remnant of the early generated subplate neuron population. J. Comp. Neurol. 282: $555-569$

Cohen GM, Sun X-M, Snowden RT, Dinsdale D and Skilleter DN (1992) Key morphological features of apoptosis may occur in the absence of internucleosomal DNA fragmentation. Biochem. J. 286: 331-334

Cohen JJ and Duke RC (1984) Glucocorticoid activation of a calcium dependent endonuclease in thymocyte nuclei leads to cell death. J. Immunol. 132: 38-42

Collins RJ, Harmon BV, Gobe GC and Kerr JFR (1992) Internucleosomal DNA cleavage should not be the sole criterion for identifying apoptosis. Int. J. Radiat. Biol. 61: 451-453

Cotran RS, Kumar V and Robbins SL (1989) Robbins' pathologic basis of disease. (Philadelphia: W.B. Saunders Company)

Ferrer I, Soriano E, Del Rio JA, Alcantara S and Auladell C (1992) Cell death and removal in the cerebral cortex during development. Prog. Neurobiol. 39: 1-43

Ferrer I, Tortosa A, Blanco R, Martin F, Serrano T, Planas A and Macaya A (1994) Naturally occurring cell death in the developing cerebral cortex of the rat. Evidence of apoptosis-associated internucleosomal DNA fragmentation. Neurosci. Letts. 182: 77-79

Finlay BL and Slattery M (1983) Local differences in the amount of early cell death in neocortex predict adult local specialization. Science 219: 1349-1351

Gavrieli Y, Sherman Y and Ben-Sasson SA (1992) Identification of programmed cell death in situ via specific labeling of nuclear DNA fragmentation. J. Cell Biol. 119: 493-501

Hinsull SM and Bellamy D (1981). Tissue homeostasis and cell death. In Cell death in biology and pathology., ID Bowen and RA Lockshin, eds. London, New York: Chapman and Hall press

Kamakaka RT, Tyree CM and Kadonaga JJ (1991) Accurate and efficient RNA polymerase II transcription with a soluble nuclear fraction derived from Drosophila embryos. Proc. Natl. Acad. Sci. USA 88: 1024-1028

Kerr JFR and Harmen BV (1991) Definition and incidence of apoptosis an historical perspective. In Apoptosis: The molecular basis of cell death., LD Tomei and FO Cope, eds. (New York: Cold Spring Harbor Laboratory)

Kerr JFR, Wyllie AH and Currie AR (1972) Apoptosis: A basic biological phenomenon with wide-ranging implications in tissue kinetics. Brit. J. Cancer 26: 239-257

Lisitsyn N, Lisitsyn N and Wigler M (1993) Cloning the difference between two complex genomes. Science 259: 946-951

Lockshin RA and Zakeri Z (1991) Programmed cell death and apoptosis. In Apoptosis: The molecular basis of cell death., LD Tomei and FO Cope, eds. (New York: Cold Spring Harbor Laboratory)

Mueller PR and Wold B (1989) In vivo footprinting of a muscle specific enhancer by ligation mediated PCR. Science 246: 780-786

Oberhammer F, Frittsch G, Pavelka M, Froschl G, Tiefenbacher R, Purchio T and Sculte-Hermann R (1992) Induction of apoptosis in cultured hepatocytes and in regressing liver by transforming growth factor- $\beta 1$ occurs without activation of an endonuclease. Toxicol. Letts. 64/65: 701-704

Oberhammer F, Wilson JW, Dive C, Morris ID, Hickman JA, Wakeling AE, Walker PR and Sikorska M (1993) Apoptotic death in epithelial cells: cleavage of DNA to 300 and/or $50 \mathrm{~kb}$ fragments prior to or in the absence of internucleosomal fragmentation. EMBO J. 112: 3679-3684 
Peitsch MC, Polzar B, Stephen H, Crompton T, MacDonald HR, Mannherz HG and Tschopp J (1993) Characterization of the endogenous deoxyribonuclease involved in nuclear DNA degradation during apoptosis (programmed cell death). EMBO. 12: $371-377$

Piquette GN, Tilly JL, Prichard LE, Simon MSC and Polan ML (1994) Detection of apoptosis in human and rat ovarian follicles. J. Soc. Gynecol. Invest. 1:297-301

Rosl F (1992) A simple and rapid method for detection of apoptosis in human cells. Nuc. Acids Res. 20: 5243

Rotello RJ, Hocker MB and Gerschenson LE (1989) Biochemical evidence for programmed cell death in rabbit uterine epithelium. Am. J. Path. 134: 491-495

Rudnicki M and McBurney MW (1987) Cell culture methods and induction of differentiation of embryonic carcinoma cell lines. In Teratocarcinoma and embryonic stem cells: a practical approach, E. J. Robertson, eds. (New York: IRL Press)

Schlissel M, Constantinescu A, Morrow T, BaxterMandPeng A(1993) Double-strand signal sequence breaks in $\mathrm{V}(\mathrm{D}) \mathrm{J}$ recombination are blunt, $5^{\prime}$-phosphorylated, RAG dependent, and cell cycle regulated. Genes and Dev. 7: 2520-2532

Schwartz LM, Smith SW, Jones MEE and Osborne BA (1993) Do all programmed cell deaths occur via apoptosis? Proc. Natl. Acad. Sci. USA 90: 980-984

Schwartz LM and Truman JW (1983) Hormonal control of rates of metamorphic development in the tobacco hornworm Manduca sexta. Dev. Biol. 99: 103-114

Shortman K, Egerton M, Spangrude GJ and Scollay R (1990) The generation and fate of thymocytes. Sem. Immunol. 2: 3-12

Steller H and Grether ME (1994) Programmed cell death in Drosophila. Neuron. 13 $1269-1274$
Surh CD and Sprent J (1994) T-cell apoptosis detected in situ during positive and negative selection in the thymus. Nature 372: 100-103

Tilly JL and Hsueh AJW (1993) Microscale autoradiographic method for the qualitative and quantitative analysis of apoptotic DNA fragmentation. J. Cell. Physiol. 154: 519-526

Tilly JL, Kowalski KI, Johnson AL and Hsueh AJW (1991) Involvement of apoptosis in ovarian follicular atresia and postovulatory regression. Endocrinol. 129: 2799 2801

Ucker DS, Obermiller PS, Eckhart W, Apgar JP, Berger NA and Meyers J (1992) Genome digestion is a dispensable consequence of physiological cell death mediated by cytotoxic T lymphocytes. Mol. Cell. Biol. 12 3060-3069

Wood KA, Dipasquale B and Youle RJ (1993) In situ labeling of granule cells for apoptosis-associated DNA fragmentation reveals different mechanisms of cell loss in developing cerebellum. Neuron 11: 621-632

Wyllie AH (1980) Glucocorticoid-induced thymocyte apoptosis is associated with endogenous endonuclease activation. Nature 284: 555-556

Wyllie $\mathrm{AH}$ (1981) Cell death: A new classification separating apoptosis from necrosis. In Cell Death in Biology and Pathology, ID Bowen and RA Lockshin, eds. (London, New York: Chapman and Hall Press)

Wyllie AH and Morris RG (1982) Hormone-induced cell death and properties of thymocytes undergoing apoptosis after glucocorticoid treatment. Am. J. Path. 109: $75-87$

Wyllie AH, Morris RG, Smith AL and Dunlop D (1984) Chromatin cleavage in apoptosis: association with condensed chromatin morphology and dependence on macromolecular synthesis. J. Pathol. 142: 67-77 